\title{
Metal-to-ligand and ligand-to-metal charge transfer in thin films of Prussian blue analogues investigated by $\mathrm{X}$-ray absorption spectroscopy
}

\author{
Sébastien Bonhommeau, ${ }^{* a}$ Niko Pontius, ${ }^{a}$ Saioa Cobo, ${ }^{b}$ Lionel Salmon, ${ }^{b}$ \\ Frank M. F. de Groot, ${ }^{c}$ Gábor Molnár, ${ }^{b}$ Azzedine Bousseksou, ${ }^{b}$ \\ Hermann A. Dürr ${ }^{a}$ and Wolfgang Eberhardt ${ }^{a}$
}

\author{
Received 22nd April 2008, Accepted 20th June 2008 \\ First published as an Advance Article on the web 6th August 2008 \\ DOI: $10.1039 / \mathbf{b 8 0 6 7 8 3 j}$
}

\begin{abstract}
A series of thin films of Prussian blue analogues is investigated by X-ray absorption spectroscopy (XAS) at the $\mathrm{Fe}, \mathrm{Co}$ and $\mathrm{Mn} \mathrm{L}_{2,3}$-edges. The ligand field multiplet theory enables us to examine accurately the electronic structure of these materials. Experimental XAS spectra of CoFe Prussian blue analogues are successfully reproduced using a ground state configuration including metal-toligand (MLCT) and ligand-to-metal charge transfer (LMCT) at the Co and $\mathrm{Fe}_{2,3}$-edges. In particular, a huge improvement is achieved for satellite peaks at the $\mathrm{Co}(\mathrm{III}) \mathrm{L}_{2,3}$-edges compared to previous calculations in the literature based on LMCT effects only. On the other hand, XAS spectra of MnFe analogues synthesized for the first time, can be reproduced conveniently by taking into account either MLCT or LMCT depending on the conditions of the sample preparation. For each thin film, the proportion of the different oxidation states of Co, Fe and $\mathrm{Mn}$ is evaluated. Unexpectedly, this analysis reveals the presence of a significant amount of a reduced phase, which turns out to be strongly dependent on the sample synthesis and storage conditions.
\end{abstract}

\section{Introduction}

Valence-tautomeric Prussian blue analogues have attracted tremendous interest because of their various spectacular magnetic properties, such as high Curie temperatures, ${ }^{1}$ first order thermal phase transitions ${ }^{2}$ and photomagnetic effects. ${ }^{3,4-10}$ Their general formula is $\mathrm{A}_{x} \mathrm{M}\left[\mathrm{M}^{\prime}(\mathrm{CN})_{6}\right]_{y} \cdot n \mathrm{H}_{2} \mathrm{O}$ where $\mathrm{A}$ is an alkali metal cation and $\mathrm{M}$ and $\mathbf{M}^{\prime}$ are divalent or trivalent transition metal cations. In this class, we are interested in the so-called $\mathrm{CoFe}$ and $\mathrm{MnFe}$ Prussian blue analogues in reference to the metal ions they contain. ${ }^{4}$ These compounds crystallize in face-centred cubic (fcc) structures. They consist of a 3D coordination network containing $\mathrm{Fe}(\mathrm{II})-\mathrm{CN}-\mathrm{M}$ (III) ( $\mathrm{M}=\mathrm{Mn}$, Co) entities in their low-temperature (LT) phase and $\mathrm{Fe}(\mathrm{III})-\mathrm{CN}-\mathrm{M}$ (II) entities in their high-temperature (HT) phase. A number of $\mathrm{Fe}(\mathrm{CN})_{6}$ sites are however vacant ${ }^{5,11}$ and filled by water molecules that bond to $\mathrm{M}$ ions through their $\mathrm{O}$ atoms. ${ }^{12}$ Noncoordinated water molecules are often observed as well. In this lattice, additional alkali metal ions fill a few tetrahedral, interstitial sites. ${ }^{5,13} \mathrm{CoFe}$ Prussian blue analogues typically undergo a thermal transition from the $\mathrm{Fe}(\mathrm{III})(\mathrm{S}=1 / 2)-\mathrm{CN}-\mathrm{Co}(\mathrm{II})(\mathrm{S}=3 / 2) \mathrm{HT}$ phase to the $\mathrm{Fe}(\mathrm{II})(\mathrm{S}=0)-\mathrm{CN}-\mathrm{Co}(\mathrm{III})(\mathrm{S}=0) \mathrm{LT}$ phase. The charge transfer between $\mathrm{Fe}$ and $\mathrm{Co}$ ions is consequently accompanied by a spin crossover at the Co ions from $\mathrm{Co}(\mathrm{II})$ in the high spin

\footnotetext{
${ }^{a}$ BESSY GmbH, Albert-Einstein-Str. 15, 12489 Berlin, Germany. E-mail: bonhommeau@bessy.de; Fax:+49-30/6392-2136

${ }^{b}$ Laboratoire de Chimie de Coordination, UPR 8241 CNRS, 205 route de Narbonne, F-31077 Toulouse cedex, France

${ }^{c}$ Department of Inorganic Chemistry and Catalysis, Utrecht

University, Sorbonnelaan 16, 3584 CA Utrecht, Netherlands
}

(HS) state to Co(III) in the low spin (LS) state. On the contrary, MnFe Prussian blue analogues show a thermally induced phase transition from the HT cubic $\mathrm{Fe}(\mathrm{III})(\mathrm{S}=$ $1 / 2)-\mathrm{CN}-\mathrm{Mn}$ (II) ( $\mathrm{S}=5 / 2)$ phase to the LT tetragonal $\mathrm{Fe}(\mathrm{II})(\mathrm{S}=0)-\mathrm{CN}-\mathrm{Mn}(\mathrm{III})(\mathrm{S}=2)$ phase accompanied by a Jahn-Teller distortion on the manganese ion. ${ }^{13,14}$

Until now many investigations have been performed on these materials using X-ray techniques, such as X-ray diffraction, ${ }^{9,13,15}$ X-ray absorption spectroscopy ${ }^{5-7,10,12,16,17}$ and X-ray magnetic circular dichroism. ${ }^{8}$ However, these studies focused on powder samples and no X-ray data are available so far for Prussian-blue-based thin films. In this paper, we present the first X-ray absorption spectroscopy (XAS) measurements on a series of $c a .50 \mathrm{~nm}$-thin films of $\mathrm{CoFe}$ and $\mathrm{MnFe}$ type Prussian blue analogues. The preparation of thin layers of Prussian blue analogues was accomplished by assembling multilayers on surfaces using alternate adsorption of cations and anions. ${ }^{18}$ In the past, this sequential assembly method has been explored on a variety of materials ${ }^{19}$ and allowed the deposition of dense, ultrathin films of Prussian blue and its analogues on various supports, with precise control over the thickness on the nanometer scale. ${ }^{20}$ Using simulations based on the ligand field multiplet (LFM) theory, ${ }^{21}$ we show that the coexistence of metal-to-ligand charge transfer (MLCT) and ligand-to-metal charge transfer (LMCT) explains the absorption properties of $\mathrm{CoFe}$ analogues at both the $\mathrm{Fe}$ and the $\mathrm{Co}$ $\mathrm{L}_{2,3}$-edges. Concerning $\mathrm{MnFe}$ Prussian blue analogues, the interplay between the observed charge transfer properties and the novel synthesis carried out is emphasized. In each case, the composition of the thin films is evaluated through the LFM simulations. 


\section{Experimental and calculation details}

\subsection{Sample preparation}

All chemicals were of analytical grade and used without further purification. $\mathrm{K}_{3}\left[\mathrm{Fe}(\mathrm{CN})_{6}\right], \mathrm{MnCl}_{2} \cdot 4 \mathrm{H}_{2} \mathrm{O}$ and $\mathrm{RbCl}$ were purchased from Sigma-Aldrich; $\mathrm{CoCl}_{2} \cdot 6 \mathrm{H}_{2} \mathrm{O}$ and $\mathrm{NaCl}$ were purchased from Fluka. The exact composition of the multilayer assemblies could not be obtained, that is the reason why samples will be named: $\mathrm{RbCoFe}, \mathrm{NaCoFe}$ and $\mathrm{RbMnFe}$.

Thin films of $\mathrm{RbCoFe}$ were assembled on $150 \mathrm{~nm}$-thick $\mathrm{Si}_{3} \mathrm{~N}_{4}$ membrane embedded in a silicon wafer (Silson Ltd) as follows (Fig. 1): the membrane was soaked alternately (total of 25 cycles) in $50 \mathrm{mM}$ water solution of $\mathrm{CoCl}_{2} \cdot 6 \mathrm{H}_{2} \mathrm{O}(1 \mathrm{~min})$, then in a water solution containing both $50 \mathrm{mM} \mathrm{K}_{3}\left[\mathrm{Fe}(\mathrm{CN})_{6}\right]$ and $100 \mathrm{mM} \mathrm{RbCl}(1 \mathrm{~min})$ at room temperature, with two rinsing phases in water between the two steps during $30 \mathrm{~s}$ (method 1). Finally, they were dried under Ar flow. Raman measurements reveal the presence of two broad bands centred at 2100 and $2142 \mathrm{~cm}^{-1}$ which can be tentatively assigned to the reduced form $\mathrm{Co}(\mathrm{II})-\mathrm{NC}-\mathrm{Fe}(\mathrm{II})$ and/or the $\mathrm{LT}$ component $\mathrm{Co}(\mathrm{III})-\mathrm{NC}-\mathrm{Fe}(\mathrm{II})$.

The same method 1 was used for the elaboration of the corresponding $\mathrm{NaCoFe}$ thin films but led to the formation of the totally reduced form. In order to limit the formation of this undesired form, a new method was developed: the membrane was soaked alternately in $50 \mathrm{mM}$ water solution of $\mathrm{CoCl}_{2}$. $6 \mathrm{H}_{2} \mathrm{O}(10 \mathrm{~s})$, then in a water solution containing both $50 \mathrm{mM} \mathrm{K}_{3}\left[\mathrm{Fe}(\mathrm{CN})_{6}\right]$ and $100 \mathrm{mM} \mathrm{NaCl}(10 \mathrm{~s})$ at room temperature, with two rinsing phases in water between the two steps for $5 \mathrm{~s}$; the six steps were carried out only 5 times (method 2). Finally, they were dried under Ar flow. Immediately after the deposition of the compound, Raman spectrum only shows a band at $2178 \mathrm{~cm}^{-1}$ assigned to the stretching cyano modes of the HT phase $\mathrm{Co}$ (II)-NC-Fe(III) but evolution of the sample with time lead to the emergence of the corresponding modes at 2095 and $2143 \mathrm{~cm}^{-1}$ attributed to the reduced and $\mathrm{LT}$ phases and the concomitant disappearance of the HT phase.

Conversely the use of both method 1 or method 2 for the formation of thin films of RbMnFe led unrelentingly to the formation of the totally reduced $\mathrm{Mn}$ (II)-NC-Fe(II) pairs (RbMnFe1). As a consequence, a third method was used: the membrane was soaked alternately (total of 5 cycles) in

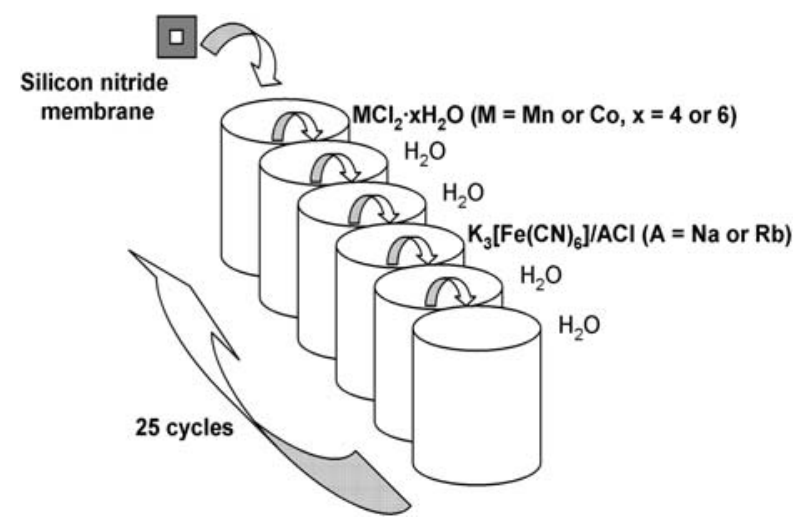

Fig. 1 Schematic representation of the multilayer sequential assembly.
$15 \mathrm{mM}$ water solution of $\mathrm{MnCl}_{2} \cdot 4 \mathrm{H}_{2} \mathrm{O}(10 \mathrm{~s})$, then in a water solution containing both $15 \mathrm{mM} \mathrm{K}_{3}\left[\mathrm{Fe}(\mathrm{CN})_{6}\right]$ and $20 \mathrm{mM}$ $\mathrm{NaCl}(10 \mathrm{~s})$ at room temperature; no rinsing phase was realized between the two steps. Finally, they were dried under Ar flow. Raman spectrum exhibits two bands at 2159 and $2169 \mathrm{~cm}^{-1}$ which have been assigned to the HT pairs $\mathrm{Mn}(\mathrm{II})-\mathrm{NC}-\mathrm{Fe}(\mathrm{III})$ (RbMnFe3). ${ }^{11}$ Another sample similarly obtained was let in an oven at $125{ }^{\circ} \mathrm{C}$ during 1 week. The composition moved from a pure HT form to a mixture of both the HT, the LT Mn(III)-NC-Fe(II) and the reduced $\mathrm{Mn}(\mathrm{II})-\mathrm{NC}-\mathrm{Fe}(\mathrm{II})$ forms (RbMnFe2) as suggested by the appearance of two broad bands centred at 2090 and $2133 \mathrm{~cm}^{-1}$ in Raman spectra. ${ }^{11} \dagger$ We can note that this time evolution is influenced by the water content which cannot be really controlled during the synthesis but varies also depending on the experimental conditions (vacuum, nitrogen atmosphere or air).

\subsection{X-Ray absorption spectroscopy}

$\mathrm{Mn}, \mathrm{Fe}$ and $\mathrm{Co} \mathrm{L}_{2,3}$-edges were recorded at the soft X-ray BESSY II beamline UE56/1-PGM-A. The photon flux of the full X-ray beam was typically reduced by a factor of 20 , i.e. to around $10^{16}$ photons $\mathrm{cm}^{-2} \mathrm{~s}^{-1}$, to avoid the degradation of the samples. All experiments were carried out in transmission geometry, which required deposition of Prussian blue analogues on very thin substrates. $150 \mathrm{~nm}$-thick silicon nitride membranes were selected as substrates because of the high $\mathrm{X}$-ray transmission of this material in the spectral region where $\mathrm{Mn}, \mathrm{Fe}$ and $\mathrm{Co} \mathrm{L}_{2,3}$-edges appeared. Regarding the number of cycles used during the multilayer sequential assembly the thickness of the thin films was evaluated to be $c a$. $50 \mathrm{~nm}$. All the reported spectra were measured under a vacuum of about $10^{-8}$ mbar at $300 \mathrm{~K}$. Measurements down to $70 \mathrm{~K}$ were also realised but they did not show any change compared to data collected at $300 \mathrm{~K}$. For comparison with simulations, the baseline was subtracted (whenever needed) by using a linear function fitted to the data below the $\mathrm{L}_{3}$-edge region and beyond the $\mathrm{L}_{2}$-edge region.

\subsection{Ligand field multiplet calculations}

In order to extract quantitative information from $\mathrm{L}_{2,3}$-edges absorption spectra, experimental XAS spectra were modelled using the so-called ligand field multiplet (LFM) theory developed by Thole ${ }^{21}$ in the framework established by Cowan ${ }^{22}$ and Butler. ${ }^{23}$ This approach takes into account all the electronic Coulomb interactions as well as the spin-orbit coupling on any electronic open shell and treats the geometrical environment of the absorbing atom through crystal field potential. The spectrum is calculated as the sum of all possible localized transitions in atoms for an electron excited from the $2 p$ level to a $3 \mathrm{~d}$ level. No attention is paid to the electric dipole allowed $2 \mathrm{p} \rightarrow 4 \mathrm{~s}$ transitions that are experimentally and theoretically found to be negligible compared to the $2 \mathrm{p} \rightarrow 3 \mathrm{~d}$ main channel. In the simplest formulation, a pure $3 \mathrm{~d}^{n}$ configuration is attributed to the $3 \mathrm{~d}$ transition ions in the ground state and

$\dagger$ Raman spectroscopy does not allow distinguishing the $\mathrm{Mn}$ (II)-NC-Fe(III) pairs observed in $\mathrm{RbMnFe}_{2}$ and $\mathrm{RbMnFe}_{3}$, contrary to XAS measurements. 
transitions between $2 \mathrm{p}^{6} 3 \mathrm{~d}^{n}$ ground state and $2 \mathrm{p}^{5} 3 \mathrm{~d}^{n+1}$ final excited state are calculated. The inter-electronic repulsions are introduced through Slater-Condon integrals, $\mathrm{F}_{\mathrm{dd}}^{2}$ and $\mathrm{F}_{\mathrm{dd}}^{4}$ for the initial state and $F_{\mathrm{dd}}^{2}, \mathrm{~F}_{\mathrm{dd}}^{4}, \mathrm{~F}_{\mathrm{pd}}^{2}, \mathrm{G}_{\mathrm{pd}}^{1}$ and $\mathrm{G}_{\mathrm{pd}}^{3}$ for the final state. The Slater-Condon integrals are calculated through an atomic Hartree-Fock model and are scaled down by a reduction factor $\kappa$ which reflects the electronic delocalisation and the covalence of the chemical bonds. The atomic spin-orbit coupling parameters, $\zeta_{3 \mathrm{~d}}$ and $\zeta_{2 \mathrm{p}}$, are calculated considering the monoelectronic potential around the ion. The octahedral surrounding of the metal ion is represented by an octahedral $\left(O_{\mathrm{h}}\right)$ crystal field potential whose strength is parameterized by 10 Dq. For a tetragonal $\left(D_{4 \mathrm{~h}}\right)$ crystal field, in case of JahnTeller distortions for instance, two other parameters must be added, namely Ds and Dt, to account for the deformation. At this point hybridization is only present through the reduction factor $\kappa$ and the ligand-metal charge transfer is not taken into account. To model LMCT effects the ground state of a $3 \mathrm{~d}^{n}$ ion is taken to be a linear combination of two appropriate configurations, $3 \mathrm{~d}^{n}$ and $3 \mathrm{~d}^{n+1} \mathrm{~L}$, where $3 \mathrm{~d}^{n+1}$ stands for an extra $3 \mathrm{~d}$ electron coming from the ligands and $\underline{L}$ for the corresponding hole on a ligand orbital. For MLCT, the ground state configurations are $3 \mathrm{~d}^{n}$ and $3 \mathrm{~d}^{n-1} \mathrm{~L}^{-}$and when both MLCT and LMCT are considered three configurations are needed, $3 \mathrm{~d}^{n-1} \mathrm{~L}^{-}, 3 \mathrm{~d}^{n}$ and $3 \mathrm{~d}^{n+1} \mathrm{~L}$, where $\mathrm{L}^{-}$represents an extra electron originating from the metal ion. The parameters EG2 (EF2) and EG3 (EF3) determine the average energy separation between $3 \mathrm{~d}^{n}, 3 \mathrm{~d}^{n+1} \underline{L}$ and $3 \mathrm{~d}^{n-1} \mathrm{~L}^{-}$configurations in the ground (final) state. EG3 and EF3 are relevant only if three configurations are considered in the ground and final states. EG2 is the energy separation between $3 \mathrm{~d}^{n}$ and $3 \mathrm{~d}^{n+1} \mathrm{~L}$ $\left(3 \mathrm{~d}^{n}\right.$ and $\left.3 \mathrm{~d}^{n-1} \mathrm{~L}^{-}\right)$configurations for a LMCT (MLCT). When simulating both LMCT and MLCT, EG2 becomes the energy separation between $3 \mathrm{~d}^{n-1} \mathrm{~L}^{-}$and $3 \mathrm{~d}^{n}$ configurations and EG3 between $3 \mathrm{~d}^{n-1} \mathrm{~L}^{-}$and $3 \mathrm{~d}^{n+1} \mathrm{~L}$ configurations. The strength of the charge transfer configurations $\mathrm{T}(\mathrm{i})$ allows for the covalent overlap of different symmetry components (i). It is represented in octahedral symmetry by the two ligand-metal charge transfer integrals $\mathrm{T}\left(\mathrm{t}_{2 \mathrm{~g}}\right)$ and $\mathrm{T}\left(\mathrm{e}_{\mathrm{g}}\right)$ and in tetragonal symmetry by the four integrals $\mathrm{T}\left(\mathrm{b}_{1 \mathrm{~g}}\right), \mathrm{T}\left(\mathrm{a}_{1 \mathrm{~g}}\right), \mathrm{T}\left(\mathrm{b}_{2 \mathrm{~g}}\right)$ and $\mathrm{T}\left(\mathrm{e}_{\mathrm{g}}\right){ }^{24}$

The purpose of the calculation lies in the computation of intensities of all possible transitions. In order to compare them to the experimental $\mathrm{L}_{2,3}$-edges XAS spectra, the theoretical transitions must be convoluted by a broadening function which takes into account the intrinsic core-hole lifetime and the instrumental resolution. In the following simulations, the full width at half maximum (FWHM) of the lifetime Lorentzian broadening function falls in the $0.2-0.4 \mathrm{eV}$ energy range over the $\mathrm{L}_{3}$-edge and the $0.3-0.6 \mathrm{eV}$ range over the $\mathrm{L}_{2}$-edge. The FWHM of the instrumental Gaussian broadening function is fixed at $0.2 \mathrm{eV}$. All simulations are carried out considering a temperature of $300 \mathrm{~K}$.

\section{XAS spectra of CoFe Prussian blue analogues}

Fig. 2 provides the experimental XAS spectra and best simulations achieved for $\mathrm{RbCoFe}$ and $\mathrm{NaCoFe}$ at the $\mathrm{Co}$ and $\mathrm{Fe} \mathrm{L}_{2,3}$-edges. The calculated XAS spectra accounting
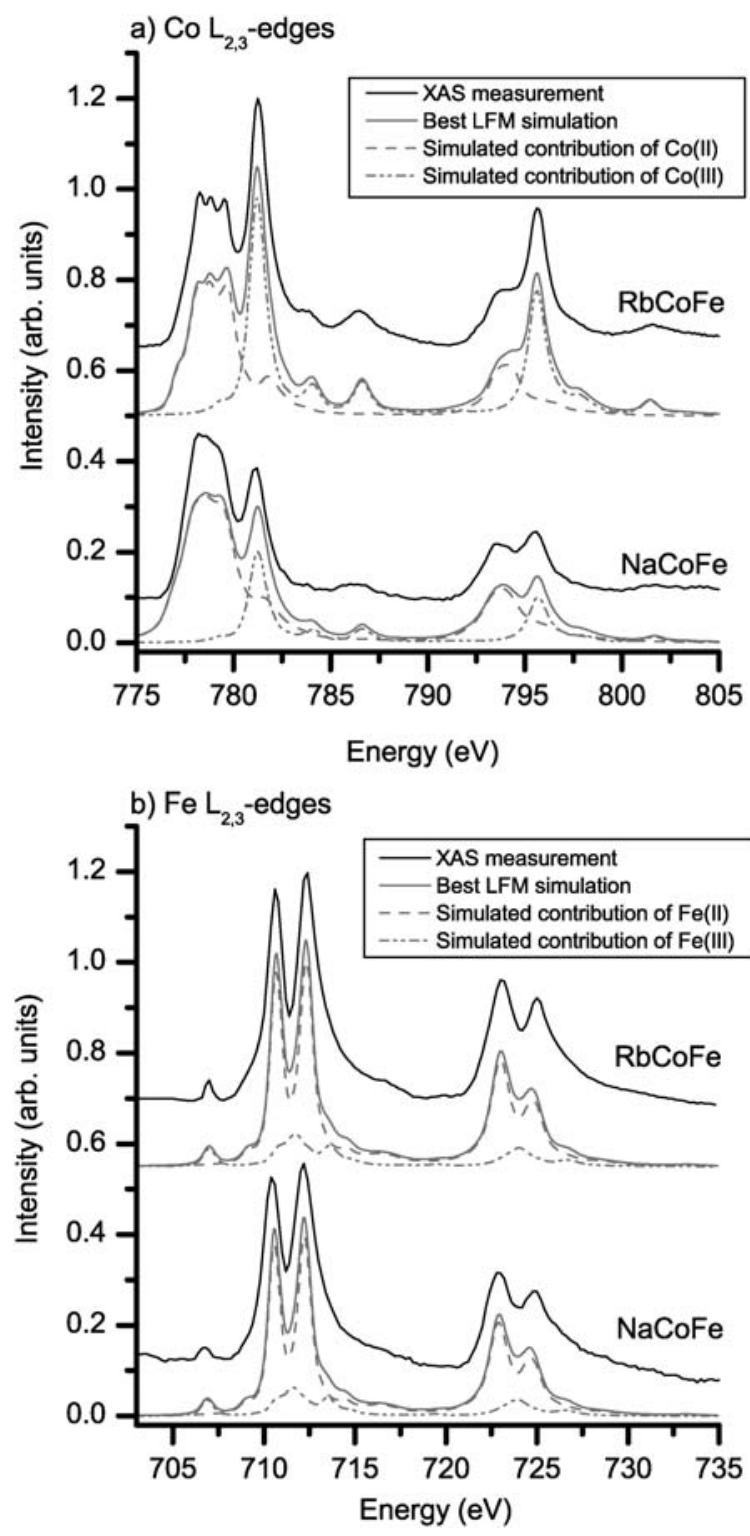

Fig. 2 Experimental XAS spectra recorded at $300 \mathrm{~K}$ and best simulations obtained for $\mathrm{RbCoFe}$ and $\mathrm{NaCoFe}$ at the $\mathrm{Co}_{2,3}$-edges (a) and the $\mathrm{Fe} \mathrm{L}_{2,3}$-edges (b). Simulations have been performed considering the ground state configurations $8 \% \mathrm{~d}^{6} \mathrm{~L}^{-}+90 \% \mathrm{~d}^{7}+$ $2 \% \mathrm{~d}^{8} \mathrm{~L}$ for Co(II) ions, $7 \% \mathrm{~d}^{5} \mathrm{~L}^{-}+63 \% \mathrm{~d}^{6}+30 \% \mathrm{~d}^{7} \mathrm{~L}$ for $\mathrm{Co}(\mathrm{III})$ ions, $43 \% \mathrm{~d}^{5} \mathrm{~L}^{-}+46 \% \mathrm{~d}^{6}+11 \% \mathrm{~d}^{7} \mathrm{~L}$ for $\mathrm{Fe}(\mathrm{II})$ ions and $32 \% \mathrm{~d}^{4} \mathrm{~L}^{-}$ $+53 \% \mathrm{~d}^{5}+15 \% \mathrm{~d}^{6} \mathrm{~L}$ for $\mathrm{Fe}(\mathrm{III})$ ions. For $\mathrm{RbCoFe}$ and $\mathrm{NaCoFe}$, the linear combinations $50 \%[\mathrm{Co}(\mathrm{II})]+50 \%[\mathrm{Co}(\mathrm{III})]$ and $75 \%[\mathrm{Co}(\mathrm{II})]+$ $25 \%[\mathrm{Co}(\mathrm{III})]$ have been used at the $\mathrm{Co}_{2,3}$-edges, respectively, but the same linear combination that is $85 \%[\mathrm{Fe}(\mathrm{II})]+15 \%[\mathrm{Fe}(\mathrm{III})]$ at the $\mathrm{Fe}$ $\mathrm{L}_{2,3}$-edges.

for experimental observations in these two materials are obtained by means of the same set of multiplet parameters (Table 1) except that the lifetime broadening is somewhat higher for the $\mathrm{NaCoFe}$ compound. This appears clearly through the lower resolved $\mathrm{Co} \mathrm{L}_{2,3}$-edges in $\mathrm{NaCoFe}$ (Fig. 2a). The width and the different features of XAS spectra at the $\mathrm{Co}_{2,3}$-edges constitute an evidence of the presence of Co ions in their oxidation state + II and + III. Peaks centred at $781.2,783.9,786.5,795.6$ and $801.5 \mathrm{eV}$ are fingerprints of 
Table 1 Ground state configurations and LFM parameters considered in order to reproduce the experimental spectra at the Co, Fe and Mn $\mathrm{L}_{2,3}$-edges

\begin{tabular}{|c|c|c|c|c|c|c|}
\hline Ground state & $\begin{array}{l}\mathrm{Co}(\mathrm{II}) \\
{ }^{4} \mathrm{~T}_{1} \\
\mathrm{t}_{2 \mathrm{~g}}^{5} \mathrm{e}_{\mathrm{g}}^{2}\end{array}$ & $\begin{array}{l}\mathrm{Co}(\mathrm{III}) \\
{ }^{1} \mathrm{~A}_{1} \\
\mathrm{t}_{2 \mathrm{~g}}^{6} \mathrm{e}_{\mathrm{g}}^{0}\end{array}$ & $\begin{array}{l}\mathrm{Fe}(\mathrm{II}) \\
{ }^{1} \mathrm{~A}_{1} \\
\mathrm{t}_{2 \mathrm{~g}}^{6} \mathrm{e}_{\mathrm{g}}^{0}\end{array}$ & $\begin{array}{l}\mathrm{Fe}(\mathrm{IIII})^{b} \\
{ }^{2} \mathrm{~B}_{2 \mathrm{~g}}\left({ }^{2} \mathrm{~T}_{2}\right) \\
\mathrm{e}_{\mathrm{g}}^{4} \mathrm{~b}_{2 \mathrm{~g}}^{1} \mathrm{~b}_{1 \mathrm{~g}}^{0} \mathrm{a}_{1 \mathrm{~g}}^{0}\left(\mathrm{t}_{2 \mathrm{~g}}^{5} \mathrm{e}_{\mathrm{g}}^{0}\right)\end{array}$ & $\begin{array}{l}\mathrm{Mn}(\mathrm{II})^{c} \mathrm{MnFe} 1 \\
{ }^{6} \mathrm{~A}_{1} \\
\mathrm{e}_{\mathrm{g}}^{2} \mathrm{~b}_{2 \mathrm{~g}}^{1} \mathrm{~b}_{1 \mathrm{~g}}^{1} \mathrm{a}_{1 \mathrm{~g}}^{1}\end{array}$ & $\begin{array}{l}\mathrm{Mn}(\mathrm{II}) \mathrm{MnFe} 2 \\
{ }^{6} \mathrm{~A}_{1} \\
\mathrm{t}_{2 \mathrm{~g}}^{3} \mathrm{e}_{\mathrm{g}}^{2}\end{array}$ \\
\hline$\kappa / \%$ & 80 & 80 & 80 & 60 & 90 & 90 \\
\hline$\zeta_{2 \mathrm{p}} / \mathrm{eV}$ & 9.75 & 9.75 & 8.20 & 8.20 & 6.85 & 6.85 \\
\hline$\zeta_{3 \mathrm{~d}} / \mathrm{eV}$ & 0.022 & 0.022 & 0.06 & 0.06 & 0.04 & 0.04 \\
\hline $10 \mathrm{Dq} / \mathrm{eV}$ & 0.5 & 2.7 & 4.2 & 3.9 & 2.0 & 0.25 \\
\hline $\mathrm{Dt} / \mathrm{eV}$ & - & - & - & -0.012 & -0.25 & - \\
\hline $\mathrm{Ds} / \mathrm{eV}$ & - & - & - & 0 & -0.2 & - \\
\hline $\mathrm{EG} 2 / \mathrm{eV}$ & -5.0 & -2.0 & 2.0 & 1.0 & 2.0 & 5.0 \\
\hline EF2/eV & -6.0 & -3.0 & 0.5 & 0.5 & 3.0 & 3.0 \\
\hline $\mathrm{EG} 3 / \mathrm{eV}$ & 1.0 & 1.0 & -2.0 & 1.0 & - & - \\
\hline $\mathrm{EF} 3 / \mathrm{eV}$ & 3.0 & 2.5 & 0 & 1.5 & - & - \\
\hline $\mathrm{T}\left(\mathrm{e}_{\mathrm{g}}\right) \mathrm{ML}^{a}$ & 0 & 2.0 & 1.0 & 0.9 & $0 / 2.0$ & - \\
\hline $\mathrm{T}\left(\mathrm{t}_{2 \mathrm{~g}}\right) \mathrm{ML}^{a}$ & 0.7 & 1.2 & 1.9 & 2.2 & 0 & - \\
\hline $\mathrm{T}\left(\mathrm{e}_{\mathrm{g}}\right) \mathrm{LM}^{a}$ & 1.0 & 3.5 & 0.9 & 2.1 & - & 2.0 \\
\hline $\mathrm{T}\left(\mathrm{t}_{2 \mathrm{~g}}\right) \mathrm{LM}^{a}$ & 0 & 0 & 0 & 0.5 & - & 1.0 \\
\hline
\end{tabular}

Co(III) ions in the LS state while peaks at 778.3, 778.8, 779.5 and $793.8 \mathrm{eV}$ characterize $\mathrm{Co}(\mathrm{II})$ ions in the HS state. ${ }^{6,10,17}$

The contribution of $\mathrm{Co}(\mathrm{II})$ ions is modelled using a weak crystal field of $0.5 \mathrm{eV}$ compatible with the expected HS state. Even though a $100 \% \mathrm{~d}^{7}$ ground state configuration allows for the contribution of $\mathrm{Co}(\mathrm{II})$ ions in the XAS spectrum of $\mathrm{CoFe}$ Prussian blue analogues, the introduction of a $68 \%$ reduction factor of the Slater integrals $\kappa$ turns out to be mandatory to improve the agreement between calculations and measurements at the $\mathrm{Co}_{3}$-edge in this case. ${ }^{6,10,17}$ In order to avoid the resort to this reduction, we chose the ground state configuration $8 \% \mathrm{~d}^{6} \mathrm{~L}^{-}+90 \% \mathrm{~d}^{7}+2 \% \mathrm{~d}^{8} \mathrm{~L}$. Here, an MLCT and an LMCT are considered and the reduction factor is maintained at $80 \%$ in accordance with the usual reduction in electron repulsion of the experimental free ion value. ${ }^{24}$ The low percentages of charge transfer configurations come from the relatively weak covalence of $\mathrm{Co}(\mathrm{II})-\mathrm{NC}$ and $\mathrm{Co}(\mathrm{II})-$ $\mathrm{O}\left(\mathrm{H}_{2} \mathrm{O}\right)$ bonds. ${ }^{6}$ Through parameters listed in Table 1 , this latter appears to be mainly due to some $\pi$ back-donation (charge transfer from $t_{2 g}$ metal orbitals to the ligand) and $\sigma$ donation (charge transfer from the ligand to the $e_{\mathrm{g}}$ metal orbitals). At this point, we need to emphasize that a small $3 \mathrm{~d}$ spin-orbit coupling $\left(\zeta_{3 \mathrm{~d}}=0.022 \mathrm{eV}\right)$ must be used to reproduce the energy position at the $\mathrm{Co}_{3}$-edge. The only way to compensate such decrease would be to bring the cubic crystal field down to almost $0 \mathrm{eV}$ in complete disagreement with former investigations about Prussian blue analogues containing Co ions. This small $3 \mathrm{~d}$ spin-orbit coupling is commonly assumed instead. ${ }^{6,10,16,17}$

The contribution of $\mathrm{Co}$ (III) ions is modelled using the ground state configurations $7 \% \mathrm{~d}^{5} \mathrm{~L}^{-}+63 \% \mathrm{~d}^{6}+30 \%$ $\mathrm{d}^{7} \underline{\mathrm{L}}$ (Fig. 2a). Both MLCT and LMCT effects are included. This contrasts with former studies where only a LMCT was taken into account to simulate experimental XAS spectra of CoFe Prussian blue analogues..$^{6,10,17}$ Fig. 3 demonstrates the effect of performing calculations using the optimised ground state configurations $62 \% \mathrm{~d}^{6}+38 \% \mathrm{~d}^{5} \mathrm{~L}^{-}$(MLCT), $77 \% \mathrm{~d}^{6}+$
$23 \% \mathrm{~d}^{7} \underline{\mathrm{L}}(\mathrm{LMCT})$ and $7 \% \mathrm{~d}^{5} \mathrm{~L}^{-}+63 \% \mathrm{~d}^{6}+30 \% \mathrm{~d}^{7} \underline{\mathrm{L}}$ (MLCT + LMCT) on the XAS spectrum of Co(III) ions. Significant changes appear for the satellite peaks at $786.5 \mathrm{eV}$ and $801.5 \mathrm{eV}$. Their intensities are greatly overestimated if the calculation is limited to MLCT and underestimated for a LMCT alone. A right balance between MLCT and LMCT effects ensures on the contrary an almost perfect agreement with the experimental XAS spectra (Fig. 2a).

Considering this MLCT + LMCT approach, Co(III) ions are in the LS state due to the relatively high cubic crystal field of $2.7 \mathrm{eV}$ (Table 1). Their $\mathrm{t}_{2 \mathrm{~g}}$ orbitals are completely filled thereby. The $\pi$ donation (charge transfer from the ligand to $t_{2 g}$ metal orbitals) is not likely to play any role accordingly (see $\mathrm{T}\left(\mathrm{t}_{2 \mathrm{~g}}\right)$ LM in Table 1 ). The $\pi$ back-donation slightly

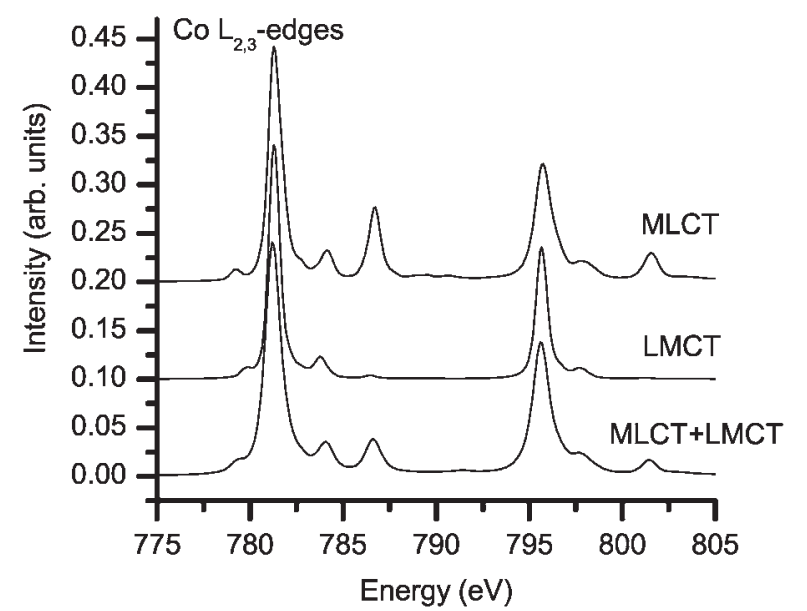

Fig. 3 LFM calculations at the $\mathrm{Co}_{2,3}$-edges using the ground state configurations $62 \% \mathrm{~d}^{6}+38 \% \mathrm{~d}^{5} \mathrm{~L}^{-}$(MLCT), $77 \% \mathrm{~d}^{6}+23 \% \mathrm{~d}^{7} \mathrm{~L}$ (LMCT) and 7\% $\mathrm{d}^{5} \mathrm{~L}^{-}+63 \% \mathrm{~d}^{6}+30 \% \mathrm{~d}^{7} \mathrm{~L}$ (MLCT + LMCT) for the XAS spectrum of $\mathrm{Co}(\mathrm{III})$ ions. Spectra are normalized with respect to the intense peak at $781.2 \mathrm{eV}$. 
affects the energy position of the two aforementioned satellite peaks and should be taken into account hence. The strongest effect is generated, however, by the $\sigma$ donation. All the peaks can be shifted in energy or significantly modified in intensity by varying it. This reveals the high covalence of $\mathrm{Co}$ (III)-ligand bonds. On the basis of calibrated intensities of reference compounds, ${ }^{25,26}$ the sum of the metal character in unoccupied $\mathrm{d}$ orbitals is indeed evaluated to be $c a$. $230 \%$, which corresponds to $58 \%$ of metal character for each empty orbital of $\mathrm{Co}(\mathrm{III})$ ions in the LS state. Furthermore, this also explains why former studies on CoFe Prussian blue analogues focused on LMCT. ${ }^{10,17}$ To account for such strong covalence, Bleuzen and coworkers use additionally a reduction factor of the Slater integrals $\kappa$ equal to $60 \%$ while a MLCT + LMCT calculation requires only an $80 \%$ factor, which is more reasonable as it has already been mentioned. Another effect supporting this latter approach lies in the $\sigma$ back-donation from $\mathrm{e}_{\mathrm{g}}$ metal orbitals to the ligand. Even though the $e_{g}$ set of $d$ orbitals in the ground state of LS Co(III) ions is empty, $\sigma$ back-donation turns out efficient because, in an $\mathrm{L}_{2,3}$-edges $\mathrm{X}$-ray absorption process, the excited state has $\mathrm{t}_{2 \mathrm{~g}}^{6} \mathrm{e}_{\mathrm{g}}^{1}$ electron configuration, which has an $e_{g}$ electron available to undergo $\sigma$ back-bonding. This charge transfer allows fitting the energy separation between the satellite peaks and is indispensable to improve the agreement with experimental XAS spectra (Fig. 2a).

Crystal fields of Co ions also give information on their structure. As pointed out by Bleuzen et al., ${ }^{12,17}$ $\mathrm{Co}(\mathrm{III})-\mathrm{NC}-\mathrm{Fe}(\mathrm{II})$ entities are linear. This implies a strong orbital interaction between $\mathrm{Co}$ ions and $\mathrm{CN}^{-}$ligands and a strong Co ligand field $(10 \mathrm{Dq}=2.7 \mathrm{eV})$ leading to $\mathrm{LS} \mathrm{Co}(\mathrm{III})$ ions. On the contrary, $\mathrm{Co}(\mathrm{II})-\mathrm{NC}-\mathrm{Fe}(\mathrm{III})$ entities should be bent because of 3D lattice strains. The much weaker orbital interaction between $\mathrm{Co}$ ions and $\mathrm{CN}^{-}$ligands provides a weaker ligand field $(10 \mathrm{Dq}=0.5 \mathrm{eV})$ whose value is in line with what is expected in case of the formation of hydrogen bonds between $\mathrm{H}_{2} \mathrm{O}$ bonded to $\mathrm{Co}$ and the $\mathrm{CN}^{-}$ligand. ${ }^{17}$

The calculated spectrum of $\mathrm{RbCoFe}$ matches nicely the experimental spectrum when supposing the presence of $50 \%$ $[\mathrm{Co}(\mathrm{II})]+50 \%[\mathrm{Co}(\mathrm{III})]$. On the other hand, we can estimate that $\mathrm{NaCoFe}$ films are filled by $75 \%[\mathrm{Co}(\mathrm{II})]+25 \%[\mathrm{Co}(\mathrm{III})]$. This difference cannot be explained in terms of the nature of the alkali ion. As the radius of the hydrated $\mathrm{Na}^{+}$cation is bigger than that of the hydrated $\mathrm{Rb}^{+}$cation, ${ }^{27}$ the substitution of $\mathrm{Rb}^{+}$by $\mathrm{Na}^{+}$should indeed favour Co(III) ions in the LS state rather than $\mathrm{Co}$ (II) in the HS state for which antibonding $\mathrm{e}_{\mathrm{g}}$ orbitals are populated leading to longer $\mathrm{Co}-\mathrm{NC}$ bonds, that is a bigger volume of the coordination sphere of the Co ion. The predominance of $\mathrm{Co}(\mathrm{II})$ ions in $\mathrm{NaCoFe}$ is more likely due to a bigger amount of $\left[\mathrm{Fe}(\mathrm{CN})_{6}\right]^{3-}$ or $\left[\mathrm{Fe}(\mathrm{CN})_{6}\right]^{4-}$ vacancies yielding a smaller quantity of alkali ions in $\mathrm{NaCoFe}$ compared to $\mathrm{RbCoFe}$ in order to preserve the electroneutrality. ${ }^{11}$ Such depletion in the number of $\mathrm{Na}^{+}$ions releases space, which favours HS species.

Measured XAS spectra plotted in Fig. $2 b$ at the Fe $\mathrm{L}_{2,3}$-edges strikingly look like the XAS spectrum of LS Fe(II) ions in $\mathrm{K}_{4}\left[\mathrm{Fe}(\mathrm{CN})_{6}\right]$ reported earlier. ${ }^{26}$ Relative intensities and energy position of peaks at 710.7, 712.3, 723.1 and $725 \mathrm{eV}$ nicely match indeed. A more accurate comparison between calculated and experimental XAS spectra reveals however the coexistence of the two oxidation states + II and + III for Fe ions in thin films of CoFe Prussian blue analogues. The peak around $707 \mathrm{eV}$ associated with the $2 \mathrm{p}^{6} \mathrm{t}_{2 \mathrm{~g}}^{5} \mathrm{e}_{\mathrm{g}}^{0} \rightarrow 2 \mathrm{p}^{6} \mathrm{t}_{2 \mathrm{~g}}^{5} \mathrm{e}_{\mathrm{g}}^{0}$ transition is effectively characteristic of LS Fe(III) since it is absent for LS Fe(II) ions having no vacant $\mathrm{t}_{2 \mathrm{~g}}$ orbitals in their ground state in octahedral symmetry.

To reproduce experimental spectra, simulations including both MLCT and LMCT are performed as suggested by Hocking et $a l^{26}$ for $\mathrm{K}_{4}\left[\mathrm{Fe}(\mathrm{CN})_{6}\right]$ and $\mathrm{K}_{3}\left[\mathrm{Fe}(\mathrm{CN})_{6}\right]$ since Prussian blue analogues contain both $\mathrm{Fe}(\mathrm{CN})_{6}$ entities. The cubic crystal field around $4 \mathrm{eV}$ is compatible with Fe ions in the LS state (Table 1). The 10Dq value of Fe(II) coincides especially well with the $4.19 \mathrm{eV}$ reported in the literature for $\left[\mathrm{Fe}(\mathrm{CN})_{6}\right]^{4-28}$ The ground state configuration yielding the best accord with measurements is $43 \% \mathrm{~d}^{5} \mathrm{~L}^{-}+46 \% \mathrm{~d}^{6}+$ $11 \% \mathrm{~d}^{7} \mathrm{~L}$ for Fe(II) ions and $32 \% \mathrm{~d}^{4} \mathrm{~L}^{-}+53 \% \mathrm{~d}^{5}+15 \% \mathrm{~d}^{6} \underline{\mathrm{L}}$ for $\mathrm{Fe}(\mathrm{III})$ ions. In thin films, the proportion of $\mathrm{d}^{5} \mathrm{~L}^{-}$configuration is somewhat higher and that of $\mathrm{d}^{7} \mathrm{~L}$ is lower than previously observed for $\mathrm{Fe}(\mathrm{CN})_{6}^{4-} \cdot{ }^{26}$ Nevertheless, in both cases, the main effect is the $\pi$ back-donation coming from the MLCT mixing into $\mathrm{CN}^{-} \pi^{*}$ orbitals of $\mathrm{t}_{2 \mathrm{~g}}$ symmetry. Furthermore, $\sigma$ back-donation into $\sigma^{*}$ molecular orbitals of the $\mathrm{CN}^{-}$ligand and $\sigma$ donation affect the spectra as well. ${ }^{26}$

The $\mathrm{Fe} \mathrm{L}_{2,3}$-edges of the XAS spectra of $\mathrm{RbCoFe}$ and $\mathrm{NaCoFe}$ are well reproduced by means of the linear combination $85 \%[\mathrm{Fe}(\mathrm{II})]+15 \%[\mathrm{Fe}(\mathrm{III})]$. It appears possible to ascribe the percentage of $\mathrm{Fe}$ (II) and $\mathrm{Fe}$ (III) sites in materials containing both ions owing to the striking difference between $\mathrm{Fe}(\mathrm{II})$ and $\mathrm{Fe}(\mathrm{III}) \mathrm{XAS}$ spectra. In particular, the quantity of LS Fe(III) ions can be determined by looking at the characteristic transition around $707 \mathrm{eV}$ (Fig. 2b).

Investigations at the $\mathrm{Co} \mathrm{L}_{2,3}$-edges show the presence of a $50 \%[\mathrm{Co}(\mathrm{II})]+50 \%[\mathrm{Co}(\mathrm{III})]$ mixture and a $85 \%[\mathrm{Fe}(\mathrm{II})]+15 \%$ $[\mathrm{Fe}(\mathrm{III})]$ mixture at the $\mathrm{Fe} \mathrm{L}_{2,3}$-edges in $\mathrm{RbCoFe}$. We can therefore assess that this thin film contains $c a$. 35-50\% diamagnetic $\mathrm{Co}(\mathrm{III})-\mathrm{NC}-\mathrm{Fe}(\mathrm{II})$ pairs corresponding to the LT phase, $35-50 \%$ reduced form $\mathrm{Co}(\mathrm{II})-\mathrm{NC}-\mathrm{Fe}(\mathrm{II}), 0-15 \% \mathrm{Co}(\mathrm{II})-\mathrm{NC}-\mathrm{Fe}(\mathrm{III})$ pairs associated to the HT phase and/or $0-15 \%$ oxidized form $\mathrm{Co}(\mathrm{III})-\mathrm{NC}-\mathrm{Fe}(\mathrm{III})$. For $\mathrm{NaCoFe}$, the proportions 75\% [Co(II)] $+25 \%[\mathrm{Co}(\mathrm{III})]$ and $85 \%[\mathrm{Fe}(\mathrm{II})]+15 \%[\mathrm{Fe}(\mathrm{III})]$ entail the coexistence of $c a \cdot 10-25 \%$ diamagnetic $\mathrm{Co}(\mathrm{III})-\mathrm{NC}-\mathrm{Fe}(\mathrm{II})$ pairs, $60-75 \%$ reduced form $\mathrm{Co}(\mathrm{II})-\mathrm{NC}-\mathrm{Fe}(\mathrm{II}), 0-15 \% \mathrm{Co}(\mathrm{II})-\mathrm{NC}-$ $\mathrm{Fe}(\mathrm{III})$ pairs and/or $0-15 \%$ oxidized form $\mathrm{Co}(\mathrm{III})-\mathrm{NC}-\mathrm{Fe}(\mathrm{III})$.

\section{XAS spectra of MnFe Prussian blue analogues}

Fig. 4 exhibits the experimental XAS spectra and best simulations achieved for two MnFe Prussian blue analogues, called $\mathrm{RbMnFe} 1$ and $\mathrm{RbMnFe} 2$, at the $\mathrm{Mn}$ and $\mathrm{Fe} \mathrm{L}_{2,3}$-edges. The presence of transitions at 639.0, 640.0, 641.4, 643.5, 650.4 and $652.3 \mathrm{eV}$ strongly supports the presence of $\mathrm{Mn}$ (II) ions (Fig. 4a). ${ }^{29}$ More precisely, measured and simulated XAS spectra of RbMnFel agree quite well if one considers Mn(II) ions in tetragonal symmetry $(\mathrm{Dt}=-0.25 \mathrm{eV}$ and $\mathrm{Ds}=-0.2 \mathrm{eV}$ ) with the ground state configuration $70 \% \mathrm{~d}^{5}+30 \% \mathrm{~d}^{4} \mathrm{~L}^{-}$ (Fig. 4a), i.e. including the MLCT phenomenon. Any other attempt (with various sets of parameters and charge transfer effects) leads to a much worse accordance. In particular, assuming a contribution of $\mathrm{Mn}$ (III) ions, whose $\mathrm{L}_{3}$-edge is 

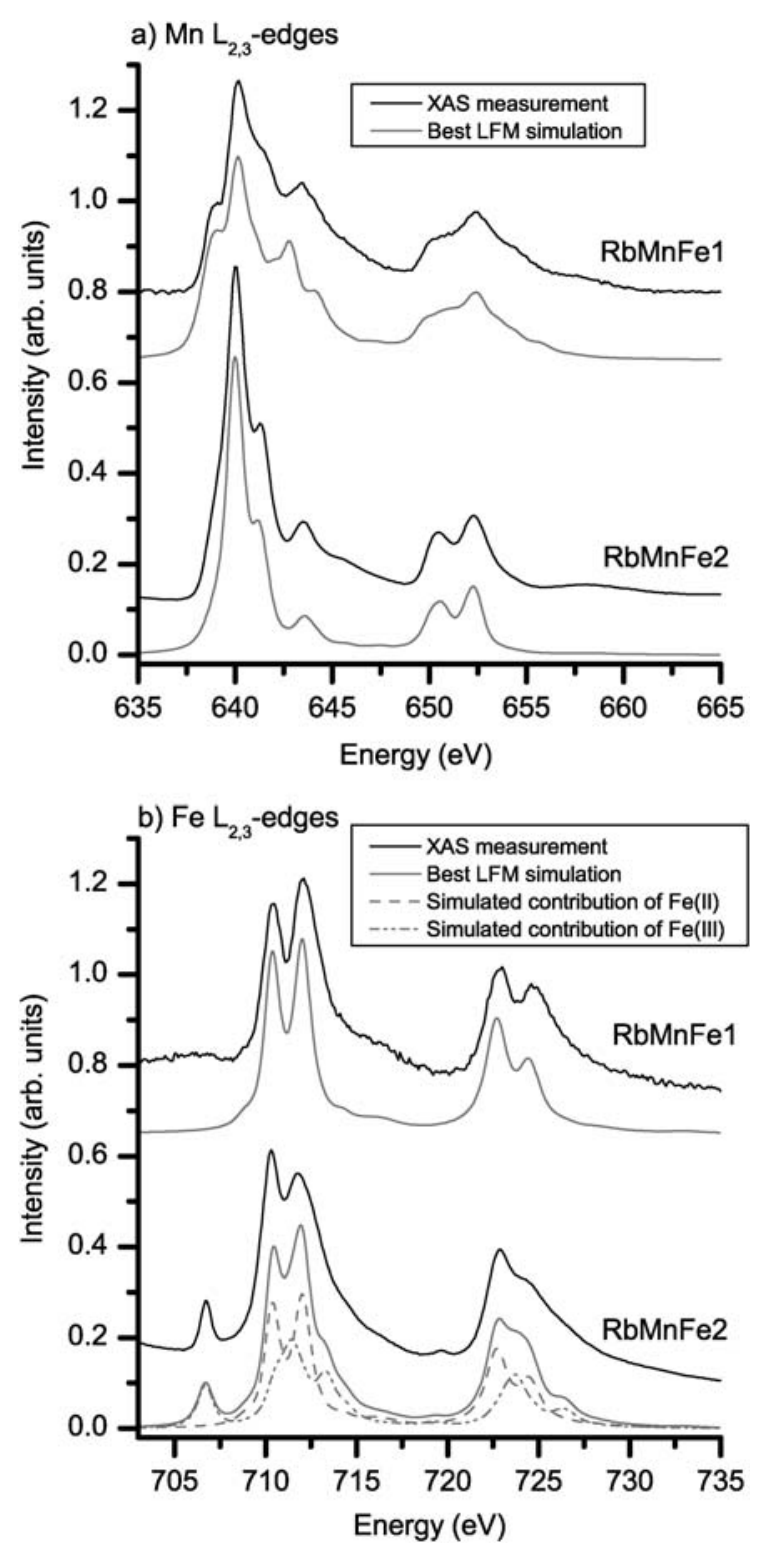

Fig. 4 Experimental XAS spectra recorded at $300 \mathrm{~K}$ and best simulations obtained for $\mathrm{RbMnFe} 1$ and $\mathrm{RbMnFe} 2$ at the $\mathrm{Mn}$ $\mathrm{L}_{2,3}$-edges (a) and the $\mathrm{Fe} \mathrm{L}_{2,3}$-edges (b). Simulations have been performed considering the ground state configurations $70 \% \mathrm{~d}^{5}+$ $30 \% \mathrm{~d}^{4} \mathrm{~L}^{-}$for $\mathrm{Mn}(\mathrm{II})$ ions in $\mathrm{RbMnFe} 1,89 \% \mathrm{~d}^{5}+11 \% \mathrm{~d}^{6} \mathrm{~L}$ for $\mathrm{Mn}(\mathrm{II})$ ions in $\mathrm{RbMnFe} 2,43 \% \mathrm{~d}^{5} \mathrm{~L}^{-}+46 \% \mathrm{~d}^{6}+11 \% \mathrm{~d}^{7} \mathrm{~L}$ for $\mathrm{Fe}(\mathrm{II})$ ions and $32 \% \mathrm{~d}^{4} \mathrm{~L}^{-}+53 \% \mathrm{~d}^{5}+15 \% \mathrm{~d}^{6} \mathrm{~L}$ for $\mathrm{Fe}(\mathrm{III})$ ions. For $\mathrm{RbMnFe} 2$, the linear combination $60 \%[\mathrm{Fe}(\mathrm{II})]+40 \%[\mathrm{Fe}(\mathrm{III})]$ has been used.

typically shifted to $1.5-2 \mathrm{eV}$ upward with respect to the $\mathrm{L}_{3}$-edge of $\mathrm{Mn}$ (II) ions when they are bonded to the same ligands, ${ }^{30}$ cannot wipe out the slight discrepancy between experiments and simulations. The latter might be rather ascribed to a state dependent lifetime broadening, which could not be taken into account in a unique way. ${ }^{31}$ Despite their surprising symmetry, $\mathrm{Mn}$ (II) ions remain in the HS state as expected for MnFe Prussian blue analogues. The only relevant charge transfer mixing parameter is associated to $\sigma$ backdonation from the highest occupied $\mathrm{a}_{1 \mathrm{~g}}$ orbitals of the metal ion to the $\mathrm{CN}^{-}$ligand (Table 1).
While the synthesis of MnFe Prussian blue analogues is carried out with reactants composed of $\mathrm{Mn}$ (II) ions in octahedral symmetry and Fe(III) ions, the experimental XAS spectrum collected at the $\mathrm{Fe} \mathrm{L}_{2,3}$-edges seems perfectly compatible with a $\mathrm{Fe}$ (II) content (Fig. 4b). ${ }^{27}$ Simulations are performed by means of a $43 \% \mathrm{~d}^{5} \mathrm{~L}^{-}+46 \% \mathrm{~d}^{6}+11 \% \mathrm{~d}^{7} \underline{\mathrm{L}}$ ground state configuration like for CoFe Prussian blue analogues. We can suggest that the reduction of $\mathrm{Fe}$ (III) sites into $\mathrm{Fe}$ (II) ions induces lattice strains, which modify the local surrounding of $\mathrm{Mn}$ (II) ions leading to the symmetry change. Although unusual, it has already been observed that such symmetry changes were possible during the reduction of Co ions. ${ }^{32}$

The experimental XAS spectrum of RbMnFe2 can be reproduced by means of $\mathrm{Mn}$ (II) ions in octahedral symmetry with the ground state configuration $89 \% \mathrm{~d}^{5}+11 \% \mathrm{~d}^{6} \underline{\mathrm{L}}$ (Fig. 4a). Compared to RbMnFe1, transitions at 639.0 and $643.5 \mathrm{eV}$ are both much weaker. The depletion at $639.0 \mathrm{eV}$ originates from the lower cubic crystal field, $0.25 \mathrm{eV}$ instead of $2.0 \mathrm{eV}$, which is probably related to a bigger amount of defects in the lattice. Indeed, unlike $\mathrm{RbMnFe} 1, \mathrm{RbMnFe} 2$ is prepared following a rapid synthesis able to generate an altered lattice. The difference at $643.5 \mathrm{eV}$ is directly linked to the occurrence of a LMCT for RbMnFe2 instead of the MLCT observed for $\mathrm{RbMnFe1.} \mathrm{We} \mathrm{can} \mathrm{stress} \mathrm{that} \mathrm{the} \mathrm{recorded} \mathrm{XAS} \mathrm{spectrum} \mathrm{of}$ $\mathrm{RbMnFe} 2$ is in fairly good agreement with previous studies realised on Mn-based organometallic compounds ${ }^{16,29,30}$ in spite of a weaker crystal field. In particular, both $\sigma$ and $\pi$ donation play an important role since metal $e_{g}$ and $t_{2 g}$ orbitals are partly filled only in the $\mathrm{HS}^{6} \mathrm{~A}_{1}\left(\mathrm{t}_{2 \mathrm{~g}}^{3} \mathrm{e}_{\mathrm{g}}^{2}\right)$ ground state of these Mn(II) ions (Table 1).

The XAS spectrum of RbMnFe2 matches the simulated spectrum obtained through a $60 \%[\mathrm{Fe}(\mathrm{II})]+40 \%[\mathrm{Fe}(\mathrm{III})]$ mixture (Fig. 4b), where the ground state configurations are still $43 \% \mathrm{~d}^{5} \mathrm{~L}^{-}+46 \% \mathrm{~d}^{6}+11 \% \mathrm{~d}^{7} \mathrm{~L}$ for Fe(II) ions and $32 \%$ $\mathrm{d}^{4} \mathrm{~L}^{-}+53 \% \mathrm{~d}^{5}+15 \% \mathrm{~d}^{6} \underline{\mathrm{L}}$ for Fe(III) ions. A reduction of initial $\mathrm{Fe}(\mathrm{III})$ ions occurs like for $\mathrm{RbMnFel}$ but it appears less complete.

From the calculated proportions of $\mathrm{Mn}$ (II), $\mathrm{Fe}(\mathrm{II})$ and $\mathrm{Fe}(\mathrm{III})$ ions, we can conclude that $\mathrm{RbMnFel}$ is composed exclusively of reduced $\mathrm{Mn}$ (II)-NC-Fe(II) pairs whereas $\mathrm{RbMnFe} 2$ contains $60 \%$ of reduced $\mathrm{Mn}$ (II)-NC-Fe(II) pairs and $40 \%$ of $\mathrm{Mn}$ (II)-NC-Fe(III) pairs that can be assigned to the HT phase. At this point, it is worth reminding that the preparation of $\mathrm{RbMnFe} 2$ involves a thermal treatment. Without this, the thin film composition becomes drastically different. Fig. 5 displays XAS spectra collected at the $\mathrm{Mn}$ and $\mathrm{Fe}_{2,3}$-edges in this case. LFM simulations suggest the exclusive presence of Fe(III) ions in the RbMnFe3 sample as it can be deduced from the existence of the strong transition around $707 \mathrm{eV}$ (Fig. 5b). At the $\mathrm{Mn} \mathrm{L}_{2,3}$-edges, they fail in reproducing the experimental XAS spectrum but a comparison with the simulation carried out for RbMnFe2 shows that only $\mathrm{Mn}$ (II) ions should be present (Fig. 5a). The double-structured $\mathrm{L}_{2}$-edge as well as the transitions at the $\mathrm{L}_{3}$-edge are fingerprints of the + II oxidation state observed also in RbMnFe1 and RbMnFe2. In $\mathrm{RbMnFe} 3$, mainly $\mathrm{Mn}$ (II)-NC-Fe(III) pairs are detected hence but they are definitely different from that constituting $\mathrm{RbMnFe} 2$. 

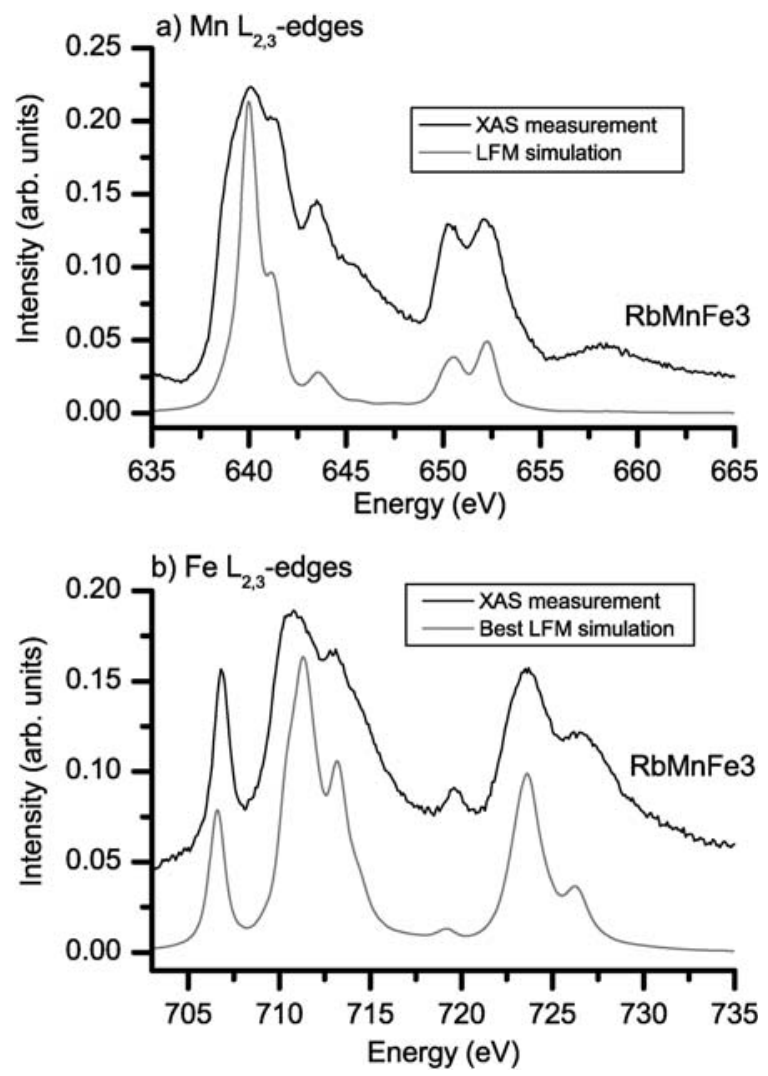

Fig. 5 Experimental XAS spectra recorded at $300 \mathrm{~K}$ and LFM simulations obtained for $\mathrm{RbMnFe} 3$ at the $\mathrm{Mn} \mathrm{L}_{2,3}$-edges (a) and the $\mathrm{Fe} \mathrm{L}_{2,3}$-edges (b). The calculated spectrum in (a) corresponds to the best simulation for RbMnFe2 (Fig. 4a). The simulation at the Fe $\mathrm{L}_{2,3}$-edges has been performed considering the ground state configuration $32 \% \mathrm{~d}^{4} \mathrm{~L}^{-}+53 \% \mathrm{~d}^{5}+15 \% \mathrm{~d}^{6} \mathrm{~L}$ only, which reveals the exclusive presence of $\mathrm{Fe}(\mathrm{III})$ ions.

\section{Conclusions}

Thin films of $\mathrm{CoFe}$ and $\mathrm{MnFe}$ Prussian blue analogues have been synthesized for the first time on thin $\mathrm{Si}_{3} \mathrm{~N}_{4}$ membranes. Such arrangement has rendered possible XAS studies in transmission geometry in order to investigate the electronic configuration of these materials. $\mathrm{RbCoFe}$ and $\mathrm{NaCoFe}$ Prussian blue analogues appear to contain a reasonable amount of $\mathrm{Co}(\mathrm{III})-\mathrm{NC}-\mathrm{Fe}$ (II) diamagnetic pairs and the XAS contribution of $\mathrm{Co}$ (III) ions appears to be strongly influenced by the $\mathrm{CN}^{-}$ligand. At this ion both MLCT and LMCT effects are of paramount importance to reproduce satellite peaks that are known to be fingerprints of charge transfer phenomena. ${ }^{24}$ Comparison with former studies ${ }^{10,17}$ shows that these diamagnetic pairs are linear and the $\mathrm{RbCoFe}$ film contain a higher amount of these pairs than the $\mathrm{NaCoFe}$ sample. This study of $\mathrm{CoFe}$ analogues reveals several similarities with powder samples famous for their photo-induced properties related to the presence of the $\mathrm{Co}(\mathrm{III})-\mathrm{NC}-\mathrm{Fe}$ (II) diamagnetic pairs, ${ }^{5}$ suggesting the interest of future photophysical investigations on these films.

Interestingly, in $\mathrm{MnFe}$ Prussian blue analogues, charge transfer properties at the $\mathrm{Mn}$ (II) ions were strongly dependent on the kinetics of the sample preparation. A sequential assembly of the coordination network leads to $\mathrm{Mn}$ (II) ions in tetragonal symmetry and exhibiting MLCT (RbMnFe1), whereas a precipitation yields $\mathrm{Mn}$ (II) ions in octahedral symmetry where LMCT is dominant ( $\mathrm{RbMnFe} 2)$. Parallel to this change, a complete reduction of $\mathrm{Fe}(\mathrm{III})$ into $\mathrm{Fe}(\mathrm{II})$ ions is induced in the first case, but it is only partial in the second case and fully vanishes for RbMnFe3. Nevertheless, XAS measurements consist of snapshots of the electronic states and further evolution of the thin films ( $\mathrm{RbMnFe} 2$ and RbMnFe3) with time cannot be excluded-as it has been inferred from Raman measurements. On the whole, however, this study indicates that charge transfer properties are tuneable depending on the sample preparation conditions, even though many details about the relation between the synthesis method and the physical properties are still under investigation.

\section{Acknowledgements}

We are indebted to the BESSY staff for their help whenever needed. Financial support by the DFG through SPP1133 is gratefully acknowledged.

\section{References}

1 T. Mallah, S. Thiébault, M. Verdaguer and P. Veillet, Science, 1993, 262, 1554; S. Ferlay, T. Mallah, R. Ouhaès, P. Veillet and M. Verdaguer, Nature, 1995, 378, 701; M. Verdaguer, A. Bleuzen, V. Marvaud, J. Vaissermann, M. Seuleiman, C. Desplanches, A. Scuiller, C. Train, R. Garde, G. Gelly, C. Lomenech, I. Roseman, P. Veillet, C. Cartier and F. Villain, Coord. Chem. Rev., 1999, 190-192, 1023; S. M. Holmes and G. S. Girolami, J. Am. Chem. Soc., 1999, 121, 5593; Ø. Hatlevik, W. E. Buschmann, J. Zhang, J. L. Manson and J. S. Miller, Adv. Mater., 1999, 11, 914.

2 N. Shimamoto, S. Ohkoshi, O. Sato and K. Hashimoto, Inorg. Chem., 2002, 41, 678; S. Ohkoshi, T. Matsuda, H. Tokoro and K. Hashimoto, Chem. Mater., 2005, 17, 81; H. Tokoro, S. Miyashita, K. Hashimoto and S. Ohkoshi, Phys. Rev. B, 2006, 73, 172415.

3 O. Sato, T. Iyoda, A. Fujishima and K. Hashimoto, Science, 1996, 272, 704; A. Goujon, O. Roubeau, F. Varret, A. Dolbecq, A. Bleuzen and M. Verdaguer, Eur. Phys. J. B, 2000, 14, 115; T. Kawamoto, Y. Asai and S. Abe, Phys. Rev. Lett., 2001, 86, 348; H. W. Liu, K. Matsuda, Z. Z. Gu, K. Takahashi, A. L. Cui, R. Nakajima, A. Fujishima and O. Sato, Phys. Rev. Lett., 2003, 90, 167403; H. Tokoro, S. Ohkoshi and K. Hashimoto, Appl. Phys. Lett., 2003, 82, 1245; M. Nishino, K. Boukheddaden, S. Miyashita and F. Varret, Phys. Rev. B, 2005, 72, 064452; F. Varret, K. Boukheddaden, E. Codjovi, I. Maurin, H. Tokoro, S. Ohkoshi and K. Hashimoto, Polyhedron, 2005, 24, 2857.

4 O. Sato, J. Tao and Y. Z. Zhang, Angew. Chem., Int. Ed., 2007, 46, 2152.

5 A. Bleuzen, C. Lomenech, V. Escax, F. Villain, F. Varret, C. Cartier dit Moulin and M. Verdaguer, J. Am. Chem. Soc., 2000, 122, 6648 .

6 C. Cartier dit Moulin, F. Villain, A. Bleuzen, M. A. Arrio, P. Sainctavit, C. Lomenech, V. Escax, F. Baudelet, E. Dartyge, J.-J. Gallet and M. Verdaguer, J. Am. Chem. Soc., 2000, 122, 6653.

7 V. Escax, A. Bleuzen, C. Cartier dit Moulin, F. Villain, A. Goujon, F. Varret and Michel Verdaguer, J. Am. Chem. Soc., 2001, 123, 12536.

8 G. Champion, V. Escax, C. Cartier dit Moulin, A. Bleuzen, F. Villain, F. Baudelet, E. Dartyge and M. Verdaguer, J. Am. Chem. Soc., 2001, 123, 12544.

9 V. Escax, A. Bleuzen, J. P. Itié, P. Munsch, F. Varret and M. Verdaguer, J. Phys. Chem. B, 2003, 107, 4763.

10 C. Cartier dit Moulin, G. Champion, J. D. Cafun, M. A. Arrio and A. Bleuzen, Angew. Chem., Int. Ed., 2007, 46, 1287. 
11 S. Cobo, R. Fernández, L. Salmon, G. Molnár and A. Bousseksou, Eur. J. Inorg. Chem., 2007, 1549.

12 A. Bleuzen, V. Escax, A. Ferrier, F. Villain, M. Verdaguer, P. Münsch and J. P. Itié, Angew. Chem., Int. Ed., 2004, 43, 3728.

13 S. Ohkoshi, H. Tokoro, M. Utsunomiya, M. Mizun, M. Abe and K. Hashimoto, J. Phys. Chem. B, 2002, 106, 2423.

14 K. Kato, Y. Moritomo, M. Takata, M. Sakata, M. Umekawa, N. Hamada, S. Ohkoshi, H. Tokoro and K. Hashimoto, Phys. Rev. Lett., 2003, 91, 255502.

15 Y. Moritomo, M. Hanawa, Y. Ohishi, K. Kato, M. Takata, A. Kuriki, E. Nishibori, M. Sakata, S. Ohkoshi, H. Tokoro and K. Hashimoto, Phys. Rev. B, 2003, 68, 144106; S. Margadonna, K. Prassides and A. N. Fitch, Angew. Chem., Int. Ed., 2004, 43, 6316.

16 M. A. Arrio, P. Sainctavit, C. Cartier dit Moulin, T. Mallah, M. Verdaguer, E. Pellegrin and C. T. Chen, J. Am. Chem. Soc., 1996, 118, 6422 .

17 V. Escax, G. Champion, M. A. Arrio, M. Zacchigna, C. Cartier dit Moulin and A. Bleuzen, Angew. Chem., Int. Ed., 2005, 44, 4798.

18 G. Decher, Science, 1997, 277, 1232; Multilayer Thin Films, ed. G. Decher and J. B. Schlenoff, Wiley-VCH, Weinheim, 2003.

19 S. Cobo, G. Molnár, J. A. Real and A. Bousseksou, Angew. Chem., Int. Ed., 2006, 45, 5786; C. M. Bell, S. W. Keller, V. M. Lynch and T. E. Mallouk, Mater. Chem. Phys., 1993, 35, 225; C. Lin and C. R. Kagan, J. Am. Chem. Soc., 2003, 125, 336.

20 R. C. Millward, C. E. Madden, I. Sutherland, R. J. Mortimer, S. Fletcher and F. Marken, Chem. Commun., 2001, 1994; W. Jin, A. Toutianoush, M. Pyrasch, J. Schnepf, H. Gottschalk, W. Rammensee and B. Tieke, J. Phys. Chem. B, 2003, 107, 12062; M. Pyrasch, A. Toutianoush, W. Jin, J. Schnepf and B. Tieke, Chem. Mater., 2003, 15, 245; J. T. Culp, J.-H. Park, I. O. Benitez,
Y.-D. Huh, M. W. Meisel and D. R. Talham, Chem. Mater., 2003, 15, 3431 .

21 B. T. Thole, G. van der Laan, J. C. Fuggle, G. A. Sawatzky, R. C. Karanatak and J. M. Esteva, Phys. Rev. B, 1985, 32, 5107.

22 R. D. Cowan, The Theory of Atomic Structure and Spectra, University of California Press, Berkeley, 1981.

23 P. H. Butler, Point group symmetry, Applications, Methods and Tables, Plenum, New York, 1991.

24 F. de Groot, Coord. Chem. Rev., 2005, 249, 31; F. de Groot, Chem. Rev., 2001, 101, 1779.

25 E. C. Wasinger, F. M. F. de Groot, B. Hedman, K. O. Hodgson and E. I. Solomon, J. Am. Chem. Soc., 2003, 125, 12894.

26 R. K. Hocking, E. C. Wasinger, F. M. F. de Groot, K. O. Hodgson, B. Hedman and E. I. Solomon, J. Am. Chem. Soc., 2006, 128, 10442.

27 Y. Marcus, Chem. Rev., 1988, 88, 1475.

28 C. S. Naiman, J. Chem. Phys., 1961, 35, 323.

29 M. M. Grush, J. Chen, T. L. Stemmler, S. J. George, C. Y. Ralston, R. T. Stibrany, A. Gelasco, G. Christou, S. M. Gorun, J. E. Penner-Hahn and S. P. Cramer, J. Am. Chem. Soc., 1996, 118, 65.

30 S. P. Cramer, F. M. F. de Groot, Y. Ma, C. T. Chen, F. Sette, C. A. Kipke, D. M. Eichhorn, M. K. Chan, W. H. Armstrong, E. Libby, G. Christou, S. Brooker, V. McKee, O. C. Mullins and J. C. Fuggle, J. Am. Chem. Soc., 1991, 113, 7937.

31 K. Okada, A. Kotani, H. Ogasawara, Y. Seino and B. T. Thole, Phys. Rev. B, 1993, 47, 6203.

32 F. Morales, F. M. F. de Groot, P. Glatzel, E. Kleimenov, H. Bluhm, M. Hävecker, A. Knop-Gericke and B. M. Weckhuysen, J. Phys. Chem. B, 2004, 108, 16201. 